\title{
Gestão de resíduos sólidos na construção civil: uma análise do relatório GRI de empresas listadas na BM\&FBOVESPA
}

\section{RESUMO}

Uma das áreas em ascensão no Brasil é a construção civil, o qual é um setor que gera impactos ambientais, dentre eles, um número elevado de resíduos sólidos. Em razão disso, este estudo tem como objetivos identificar e avaliar o que as empresas do ramo da construção civil listadas na BM\&FBOVESPA evidenciam em seus relatórios de sustentabilidade relativamente à gestão de seus resíduos. Para atender aos objetivos propostos, foram pesquisados os relatórios de sustentabilidade das empresas listadas na BM\&FBOVESPA do setor de construção civil. Os resultados mostraram que pequena parte do total de empresas listadas divulga o relatório de sustentabilidade e que, das duas empresas identificadas, após a análise das informações efetivamente divulgadas, uma apresentou dados referentes a $96 \%$ dos itens da Categoria Ambiental da Global Reporting Initiative (GRI), e a outra apresentou apenas $19 \%$ dos itens. Além disso, em ambas as empresas foram identificados itens em que a divulgação foi feita de forma parcial ou sequer foi feita. $O$ estudo conclui que mesmo a construção civil sendo uma área em expansão e geradora de resíduos, são poucas as empresas que apresentam relatório socioambiental.

Palavras-chave: Resíduos sólidos. Construção civil. Sustentabilidade ambiental.

\author{
Fabiana Frigo Souza \\ fabiiana_fs@hotmail.com \\ Graduada em Ciências Contábeis \\ Universidade Federal de Santa Catarina \\ Paulo Roberto Batista Júnior \\ paulorobertobatistajunior@hotmail.com \\ Graduado em Ciências Contábei. \\ Universidade Federal de Santa Catarina \\ Denize Demarche Minatti Ferreira \\ dminatti@terra.com.br \\ Doutoranda em Contabilidade \\ Universidade Federal de Santa Catarina \\ Luiz Felipe Ferreira \\ luiz.felipe@ufsc.br \\ Doutor em Engenharia Ambiental \\ Universidade Federal de Santa Catarina
}




\section{INTRODUÇÃO}

A construção civil é uma área de grande importância na indústria brasileira, com um forte indicativo de crescimento econômico (IPEA, 2012). No entanto, assim como tantas outras, provoca impactos ambientais, principalmente pela geração de resíduos. De acordo com Spadotto et al. (2011, p. 173), "a construção civil é responsável por vários reflexos, ao local e região onde se instala a obra, causados por suas atividades direta ou indiretamente", o que significa que a construção civil não causa apenas impactos ambientais, mas também impactos sociais e econômicos. Em relação aos impactos ambientais, além da utilização da área e da energia, a construção civil gera resíduos sólidos, seja na própria construção, seja na demolição. Esses resíduos normalmente são descartados de forma inadequada e geram impacto ambiental. Azevedo, Perstok e Moraes (2006, p. 65) ressaltam que "praticamente todas as atividades desenvolvidas na construção civil são geradoras de resíduos, comumente chamados entulho ou resíduo de construção e demolição (RCD), ou, ainda, como atualmente tem sido denominado, resíduo da construção civil (RCC)".

Segundo Silva e Fernandes (2012), o setor da construção civil é um dos maiores geradores de resíduos sólidos atualmente, e os resíduos originados durante a construção ou demolição são de extrema importância no montante que é produzido nos centros urbanos. De acordo com dados do Diagnóstico dos Resíduos Sólidos da Construção Civil, são gerados 31 milhões de toneladas por ano de resíduos sólidos provenientes da construção civil (IPEA, 2012). Esses resíduos constituem uma parte representativa do total de lixo produzido nas cidades, o que faz com que a área passe a ser alvo de constantes pesquisas e legislações que apresentem normas a ser seguidas, evitando a geração de impactos maiores.

Entre as normas que regem a geração e destinação dos resíduos sólidos, pode-se citar a Resolução n 307/2002, do Conselho Nacional do Meio Ambiente (CONAMA) e a Lei no 11.445/2007 (BRASIL, 2007).

Com base nessa perspectiva, surge a problemática da pesquisa: o que as empresas do ramo da construção civil listadas na BM\&FBOVESPA evidenciam em seus relatórios de sustentabilidade relativamente à gestão de resíduos sólidos? Partindo dessa problemática, os objetivos aqui propostos são identificar e avaliar o que as empresas do ramo da construção civil listadas na BM\&FBOVESPA demonstram em seus relatórios de sustentabilidade no que diz respeito à gestão de resíduos sólidos.

O estudo contribui na avaliação da divulgação por parte das empresas do ramo da construção civil de informações no que concerne à sua política com a geração de resíduos sólidos, considerando o que a legislação determina, e na avaliação da adoção por parte das empresas do ramo da construção civil das práticas descritas na legislação quanto ao tratamento de resíduos sólidos produzidos.

\section{REVISÃO BIBLIOGRÁFICA}

Este capítulo está dividido em três seções: construção civil, apresentando as características do segmento; ressaltando em especial a questão dos resíduos gerados e a legislação. A segunda seção traz as informações pertinentes ao relatório de sustentabilidade da Global Reporting Initiative; e, por fim a seção de estudos anteriores contempla resultados já obtidos em pesquisas da mesma natureza deste artigo.

\subsection{Construção civil: resíduos gerados e legislação}

O setor de construção civil possui algumas particularidades, que foram citadas por Toledo, Abreu e Jugles (2000), como, por exemplo, a vida útil longa dos produtos e a dependência de outros setores industriais.

Conforme o Relatório Prospectivo Setorial, trata-se de um setor de grande importância para o desenvolvimento econômico e social do país, destacando-se pela quantidade de atividades que intervêm em seu ciclo de produção, gerando consumo de bens e serviços de outros setores, além do fato de absorver grande parte da mão de obra não especializada (CGEE, 2009). Nos últimos quatro anos, o segmento de edificações, em particular, vem passando por uma significativa transformação, saindo de um longo período com poucos investimentos, para um cenário de crescimento com a disponibilidade de recursos em abundância, com grandes obras em andamento e fortes investimentos imobiliários. 
Diante do cenário de crescimento, a construção civil tende a gerar uma quantidade maior de resíduos em seus canteiros de obras. A extração de minerais e outras atividades ficaram conhecidas como sendo geradoras de danos ambientais e, em virtude disso, atualmente o setor tem-se focado em minimizar ou extinguir seus efeitos negativos no que diz respeito ao meio ambiente (SABADO; FARIAS FILHO, 2011).

A Lei no 11.445/2007 estabelece diretrizes quanto ao saneamento básico, trazendo não apenas definições e políticas de saneamento básico, como as características e classificações inerentes aos resíduos sólidos (BRASIL, 2007).

Os resíduos sólidos gerados pela construção civil estão inseridos nessa legislação no art. 30, no qual a lei expõe o que é considerado saneamento básico, quando se trata sobre a limpeza urbana e o manejo de resíduos sólidos. Saneamento básico é definido como o "conjunto de atividades, infraestruturas e instalações operacionais de coleta, transporte, transbordo, tratamento e destino final do lixo doméstico e do lixo originário da varrição e limpeza de logradouros e vias públicas" (BRASIL, 2007).

A Lei no 12.305/10 instituiu a Política Nacional de Resíduos sólidos cujo objetivo é a prevenção e a redução de geração de resíduos sólidos, visando ao consumo sustentável, aumento da reciclagem e da reutilização dos resíduos sólidos gerados e sua correta destinação (BRASIL, 2010).

Segundo a Lei n 12.305/10, o gerenciamento de resíduos sólidos pode ser definido como o

conjunto de ações exercidas, direta ou indiretamente, nas etapas de coleta, transporte, transbordo, tratamento e destinação final ambientalmente adequada dos resíduos sólidos e disposição final ambientalmente adequada dos rejeitos, de acordo com plano municipal de gestão integrada de resíduos sólidos ou com o plano de gerenciamento de resíduos sólidos, exigidos na forma desta Lei (BRASIL, 2010).

Como resíduos sólidos, a Lei define que é todo

material, substância, objeto ou bem descartado resultante de atividades humanas em sociedade, a cuja destinação final se procede, se propõe proceder ou se está obrigado a proceder, nos estados sólido ou semissólido, bem como gases contidos em recipientes e líquidos cujas particularidades tornem inviável o seu lançamento na rede pública de esgotos ou em corpos d'água, ou exijam para isso soluções técnica ou economicamente inviáveis em face da melhor tecnologia disponível (BRASIL, 2010).

O quadro 1 apresenta a classificação dos resíduos sólidos de acordo com o art. 13 da Lei n 12.305/10. 
Quadro 1 - Classificação dos resíduos sólidos

\begin{tabular}{|c|c|c|}
\hline \multirow{11}{*}{ Quanto à origem } & a) resíduos domiciliares & $\begin{array}{c}\text { Os originários de atividades domésticas em } \\
\text { residências urbanas. }\end{array}$ \\
\hline & b) resíduos de limpeza urbana & $\begin{array}{l}\text { Os originários da varrição, limpeza de } \\
\text { logradouros e vias públicas e outros serviços de } \\
\text { limpeza urbana. }\end{array}$ \\
\hline & c) resíduos sólidos urbanos & Os englobados nas alíneas "a" e "b". \\
\hline & $\begin{array}{l}\text { d) resíduos de estabelecimentos } \\
\text { comerciais e prestadores de serviços }\end{array}$ & $\begin{array}{l}\text { Os gerados nessas atividades, excetuados os } \\
\text { referidos nas alíneas "b", "e", "g", " } \mathrm{h}^{\prime} \mathrm{e} \text { "j". }\end{array}$ \\
\hline & $\begin{array}{l}\text { e) resíduos dos serviços públicos de } \\
\text { saneamento básico }\end{array}$ & $\begin{array}{c}\text { Os gerados nessas atividades, excetuados os } \\
\text { referidos na alínea "c". }\end{array}$ \\
\hline & f) resíduos industriais & $\begin{array}{l}\text { Os gerados nos processos produtivos e } \\
\text { instalações industriais. }\end{array}$ \\
\hline & g) resíduos de serviços de saúde & $\begin{array}{l}\text { Os gerados nos serviços de saúde, conforme } \\
\text { definido em regulamento ou em normas esta- } \\
\text { belecidas pelos órgãos do Sisnama e do SNVS. }\end{array}$ \\
\hline & h) resíduos da construção civil & $\begin{array}{c}\text { Os gerados nas construções, reformas, reparos e } \\
\text { demolições de obras de construção civil, inclu- } \\
\text { ídos os resultantes da preparação e escavação } \\
\text { de terrenos para obras civis. }\end{array}$ \\
\hline & i) resíduos agrossilvopastoris & $\begin{array}{c}\text { Os gerados nas atividades agropecuárias e } \\
\text { silviculturais, incluídos os relacionados a insu- } \\
\text { mos utilizados nessas atividades. }\end{array}$ \\
\hline & j) resíduos de serviços de transportes & $\begin{array}{l}\text { Os originários de portos, aeroportos, terminais } \\
\text { alfandegários, rodoviários e ferroviários e passa- } \\
\text { gens de fronteira. }\end{array}$ \\
\hline & k) resíduos de mineração & $\begin{array}{l}\text { Os gerados na atividade de pesquisa, extração } \\
\text { ou beneficiamento de minérios. }\end{array}$ \\
\hline \multirow[t]{2}{*}{$\begin{array}{l}\text { Quanto à } \\
\text { periculosidade }\end{array}$} & a) resíduos perigosos & $\begin{array}{c}\text { Aqueles que, em razão de suas características } \\
\text { de inflamabilidade, corrosividade, reatividade, } \\
\text { toxicidade, patogenicidade, carcinogenicidade, } \\
\text { teratogenicidade e mutagenicidade, apresen- } \\
\text { tam significativo risco à saúde pública ou à } \\
\text { qualidade ambiental, de acordo com lei, regula- } \\
\text { mento ou norma técnica. }\end{array}$ \\
\hline & b) resíduos não perigosos & Aqueles não enquadrados na alínea "a". \\
\hline
\end{tabular}

O CONAMA tem como objetivo dispor sobre a Política Nacional do Meio Ambiente e trouxe a Resolução no 307/2002 - em virtude da geração de resíduos advindos da construção civil -, que estabelece diretrizes quanto à gestão de resíduos sólidos gerados pela construção civil (BRASIL, 2002).

A Resolução $\mathrm{n}$ ○ 307/2002 do CONAMA define que os resíduos da construção civil

são os provenientes de construções, reformas, reparos e demolições de obras de construção civil, e os resultantes da preparação e da escavação de terrenos, tais como: tijolos, blocos cerâmicos, concreto em geral, solos, rochas, metais, resinas, colas, tintas, madeiras e compensados, forros, argamassa, gesso, telhas, pavimento asfáltico, vidros, plásticos, tubulações, fiação elétrica etc., comumente chamados de entulhos de obras, caliça ou metralha (BRASIL, 2002).

Portanto, todo aquele material que restou das construções e que não foi reutilizado é tratado como resíduo sólido proveniente da construção civil.

Esses resíduos, quando reutilizados, podem gerar economia para a empresa e ainda evitar ou diminuir os impactos ambientais gerados pelo setor. Em razão disso, a Resolução n 307/2002 do CONAMA classifica 
os resíduos sólidos em quatro classes distintas, levando em conta a possibilidade ou não de reciclagem/ reutilização desses resíduos:

I - Classe A - são os resíduos reutilizáveis ou recicláveis como agregados, tais como: a) de construção, demolição, reformas e reparos de pavimentação e de outras obras de infraestrutura, inclusive solos provenientes de terraplanagem;

b) de construção, demolição, reformas e reparos de edificações: componentes cerâmicos (tijolos, blocos, telhas, placas de revestimento etc.), argamassa e concreto;

c) de processo de fabricação e/ou demolição de peças pré-moldadas em concreto (blocos, tubos, meio-fios etc.) produzidas nos canteiros de obras;

II - Classe B - são os resíduos recicláveis para outras destinações, tais como: plásticos, papel, papelão, metais, vidros, madeiras e gesso;

III - Classe C - são os resíduos para os quais não foram desenvolvidas tecnologias ou aplicações economicamente viáveis que permitam a sua reciclagem ou recuperação;

IV - Classe D - são resíduos perigosos oriundos do processo de construção, tais como tintas, solventes, óleos e outros ou aqueles contaminados ou prejudiciais à saúde oriundos de demolições, reformas e reparos de clínicas radiológicas, instalações industriais e outros, bem como telhas e demais objetos e materiais que contenham amianto ou outros produtos nocivos à saúde (BRASIL, 2002).

Com base nas classificações disponíveis, as empresas podem preservar o meio ambiente e motivar ações socioambientais que melhoram a sua imagem e a qualidade de vida dos usuários, e, ainda, gerar renda, tendo, assim, melhores resultados.

Nesse sentido, pela importância que a expansão do setor tem e também considerando que está intimamente ligado às questões ambientais, faz-se necessário apresentar conceitos estabelecidos pela Lei $n^{\circ}$ 9.985/2000, principalmente os citados neste estudo, preservação e conservação (BRASIL, 2000).

Preservação é o conjunto de métodos, procedimentos e políticas que visem à proteção em longo prazo das espécies, habitat e ecossistemas, além da manutenção dos processos ecológicos, prevenindo a simplificação dos sistemas naturais. Conservação da natureza é o manejo do uso humano da natureza, compreendendo a preservação, a manutenção, a utilização sustentável, a restauração e a recuperação do ambiente natural, a fim de que possa produzir o maior benefício, em bases sustentáveis, às atuais gerações, e aspirações das gerações futuras.

\subsection{Global Reporting Initiative}

Criada em 1997, a GRI"é uma organização multistakeholder, sem fins lucrativos, que desenvolve a estrutura de relatórios de sustentabilidade" (BEUREN; DOMENICO; CORDEIRO, 2013, p. 22) e tem como objetivo "melhorar a qualidade, o rigor e a aplicabilidade dos relatórios de sustentabilidade" (GRI, 2006, p. 1).

Segundo Ferreira et al. (2009), a transparência sobre os impactos econômicos, ambientais e sociais tornou-se fundamental para dar credibilidade às empresas para os stakeholders, por meio do fornecimento de informações a respeito da sustentabilidade empresarial, surgindo a necessidade de uma estrutura de conceitos globais em linguagem coerente e métrica. Dessa forma, a GRI tem como missão "[...] satisfazer essa necessidade, oferecendo uma estrutura confiável para a elaboração de relatórios de sustentabilidade, que possa ser usada por organizações de todos os tamanhos, setores e localidades" (GRI, 2006, p. 2).

Rosa et al. (2013, p. 99-101) esclarecem que a GRI"vem auxiliando as empresas a medirem e comunicarem seu desempenho econômico, ambiental e social" por intermédio do relatório de sustentabilidade que vem destacando-se no cenário mundial. Tal relatório foi "desenvolvido para auxiliar as organizações a medirem e comunicarem seu desempenho econômico, ambiental e social"; além disso, por ter destaque internacional, passou a ser uma base importante para a comparação de informações.

Segundo a GRI (2006, p. 3), "elaborar relatórios de sustentabilidade é a prática de medir, divulgar e prestar contas para stakeholders internos e externos do desempenho organizacional visando o desenvolvimento sustentável". Assim sendo, seu relatório possui uma estrutura com indicadores internos e externos de 
sustentabilidade ambiental (BEUREN; DOMENICO; CORDEIRO, 2013).

"De todos os organismos que apresentam diretrizes sobre gestão ambiental ou geração de informações ambientais, este é o que parece mais completo e abrangente com suas diretrizes" (NOSSA, 2002, p. 122). O que contribui para tal observação é o fato de que, além do processo ser multistakeholder, o relatório de sustentabilidade apresentado pela GRI baseia-se em um tripé em que são evidenciados os impactos econômicos, ambientais e sociais.

Com o objetivo de garantir a transparência, que aqui é definida como"divulgação completa de informações sobre os temas e indicadores necessários para refletir os impactos e possibilitar a tomada de decisão pelos stakeholders" (GRl, 2006, p. 6), foram criadas orientações e estabelecidos princípios para definir o conteúdo, garantir a qualidade e estabelecer os limites do relatório. As orientações descrevem quais medidas devem ser tomadas a fim de decidir o que relatar. Elas dão as diretrizes para definir o conteúdo e limite do relatório, já os princípios direcionam a escolha do conteúdo e a busca da qualidade, apontando os objetivos que devem ser atingidos por um relatório.

\subsection{Estudos correlatos no segmento}

A sociedade tem exigido que os diferentes setores se posicionem quanto às suas atividades e à relação destas com as questões ambientais. Assim, para atender a tais necessidades, verifica-se que estudos referentes à gestão de resíduos e informações de natureza ambiental vêm se tornando uma prática crescente. Diante desse fato, vários autores têm direcionado suas pesquisas para a construção civil e a geração de resíduos.

Azevedo, Kiperstok e Moraes (2006), em seu trabalho sobre os resíduos da construção civil em Salvador, tinham como objetivo discutir o impacto ambiental provocado pela geração crescente de resíduos da construção civil. Como resultados, os autores sugeriram medidas para a prevenção de geração de resíduos, bem como um modelo para o fluxo destes, com isso, a geração de resíduos diminuiria em $30 \%$.

Ferreira, Noschang e Ferreira (2009) realizaram uma pesquisa, buscando identificar como a construção civil poderia contribuir em ações voltadas para a sustentabilidade empresarial. Os autores concluíram que os problemas ambientais oriundos da construção civil podem ser gerados pela deposição incorreta dos resíduos e que, se forem aplicados os materiais de forma corretamente, o impacto é reduzido, além disso, há a possibilidade de uso de materiais recicláveis e reutilizáveis.

Silva e Fernandes (2012) levantaram os principais impactos ambientais ocorridos por causa da falta de gestão dos Resíduos de Construção e Demolição (RCD) em Uberaba/MG. Entre as conclusões, os autores constataram que a cidade de Uberaba não tinha implementado um sistema de gerenciamento dos RCDs, que a sua população não estava educada e sensibilizada ambientalmente quanto aos RCDs e que a solução para os impactos causados pelos resíduos de construção e demolição gerados na cidade seria a criação de uma planta para reciclagem desses materiais.

Silva et al. (2006) realizaram uma pesquisa tendo como finalidade o estudo das práticas de gestão de resíduos sólidos da construção civil implementadas pelo Poder Público Municipal na cidade de Belo Horizonte/MG. Os resultados apontaram que houve a implementação de um conjunto de políticas e práticas de gestão de resíduos de construção. Além disso, os resultados indicam que houve benefícios econômicos, sociais e ambientais.

Baptista Junior e Romanel (2013), em seu estudo, tinham como objetivo discutir os principais aspectos relacionados à geração de resíduos da construção civil, tendo como ponto de vista a sustentabilidade das edificações. No resultado, os autores sugeriram um plano de gestão circular, obrigando a separação de materiais, implantação de pontos de recolhimento e a instalação de centros de tratamentos de resíduos de construção civil.

\section{METODOLOGIA}

A pesquisa foi realizada no conteúdo do sítio eletrônico da BM\&FBOVESPA, buscando as empresas do setor da construção civil e, de posse da relação, foram acessados os relatórios de sustentabilidade divulgados por tais empresas no ano base de 2013. 
Quanto aos objetivos, a pesquisa caracteriza-se como descritiva. Cervo e Bervian (2002, p. 66) esclarecem que "a pesquisa descritiva observa, registra, analisa e correlaciona fatos ou fenômenos (variáveis) sem manipulá-los".

Em relação aos procedimentos, trata-se de uma pesquisa bibliográfica, que é definida como sendo "desenvolvida com base em material já elaborado, constituído principalmente de livros e artigos científicos" (GIL, 2002, p. 44).

No que diz respeito à abordagem do problema, trata-se de uma pesquisa qualitativa. Creswell (2007, p. 35) explica que, na pesquisa qualitativa, "o investigador sempre faz alegações de conhecimento com base principalmente ou em perspectivas construtivistas [...] ou em perspectivas reinvindicatórias/participatórias [...] ou em ambas".

As empresas foram identificadas por meio da listagem do setor de construção civil da BM\&FBOVESPA, no qual se acessou o conteúdo dos sítios eletrônicos, obtendo-se um total de vinte empresas (Quadro 2). Foram identificadas apenas duas empresas que possuem o relatório de sustentabilidade, o que representa $10 \%$ do total das empresas listadas no setor de construção civil.

Quadro 2 - Empresas listadas na BM\&FBOVESPA no setor de construção civil

\begin{tabular}{|c|c|}
\hline EMPRESA & SELECIONADA \\
\hline BROOKFIELD INCORPORAÇÕES S. A. & Não \\
\hline CONSTRUTORA ADOLPHO LINDENBERG S. A. & Não \\
\hline CR2 EMPREENDIMENTOS IMOBILIÀRIOS S. A. & Não \\
\hline CYRELA BRAZIL REALTY S. A. EMPREEND E PART. & Não \\
\hline DIRECIONAL ENGENHARIA S. A. & Sim \\
\hline EVEN CONSTRUTORA E INCORPORADORA S. A. & Não \\
\hline EZ TEC EMPREEND. E PARTICIPACOES S. A. & Não \\
\hline GAFISA S. A. & Não \\
\hline HELBOR EMPREENDIMENTOS S. A. & Não \\
\hline JHSF PARTICIPACOES S. A. & Não \\
\hline JOAO FORTES ENGENHARIA S. A. & Sim \\
\hline MRV ENGENHARIA E PARTICIPACOES S. A. & Não \\
\hline PDG REALTY S. A. EMPREEND E PARTICIPACOES & Não \\
\hline RODOBENS NEGOCIOS IMOBILIARIOS S. A. & Não \\
\hline ROSSI RESIDENCIAL S. A. & Não \\
\hline SERGEN SERVICOS GERAIS DE ENG S. A. & Não \\
\hline TECNISA S. A. & Não \\
\hline TGLT S. A & Não \\
\hline TRISUL S. A. & Não \\
\hline VIVER INCORPORADORA E CONSTRUTORA S. A. & \\
\hline Fon & Dados a PSquis (2015) \\
\hline
\end{tabular}

Fonte: Dados da pesquisa (2015)

A amostra desta pesquisa para a análise de dados constitui-se da Even Construtora e Incorporadora S. A. e da MRV Engenharia e Participações S. A., que divulgam seus relatórios de sustentabilidade.

Para esta análise, foram coletadas informações dos relatórios de sustentabilidade de 2012 e 2013, respectivamente, os relatórios de sustentabilidade das diretrizes G3 e G4 do GRI. Importante destacar que as diretrizes apresentadas pelos relatórios G4 do GRI, além de facilitar o acesso das informações divulgadas, também aceitam a publicação do relatório com conteúdo e indicadores para dois ou mais períodos, permitindo, desse modo, identificar as variações ocorridas e um maior grau de comparabilidade.

Após a coleta dos relatórios de sustentabilidade, foi analisada a qualidade das informações constantes no GRI, diretrizes G3 ou G4, tendo como base os dados informados no relatório de sustentabilidade das empresas. 
Como premissa, adotaram-se como referência as diretrizes da G4 do GRI, considerando o grau de orientações apresentado por cada empresa, quando comparadas às diretrizes da G3 do GRI.

\section{APRESENTAÇÃO E ANÁLISE DOS RESULTADOS}

Neste tópico, serão apresentados os dados coletados e feita a análise dos resultados dividido em dois itens, um referente a cada empresa estudada. A coleta de dados ocorreu nos relatórios dos períodos de 2011 a 2013, contemplados em informações divulgadas nos documentos nos anos de 2012 a 2014. A avaliação das divulgações ocorreu por meio da análise de conteúdo dos indicadores demonstrados nas publicações específicas do relatório de sustentabilidade da GRI.

\subsection{EVEN Construtora e Incorporadora S. A.}

A EVEN Construtora e Incorporadora S. A. vem publicando seu relatório de sustentabilidade desde 2008. Em seu relatório, informa que é uma das pioneiras no Brasil na construção sustentável, desenvolvendo práticas como utilização de formas para concreto feitas de plástico e reutilizando os resíduos gerados nas construções, assim como mecanismos de controle sobre a geração de resíduos, executando auditorias nos canteiros de obras.

Em 2013, foram geradas mais de 59 mil toneladas de resíduos, que são separados, ainda nos canteiros de obras, de acordo com o seu tipo (gesso, entulho, misturados ou mix, madeira e recicláveis).

Com a implementação de projetos de logística reversa, conforme contemplado na Política Nacional de Resíduos, a empresa devolveu aos fornecedores mais de 469 toneladas de entulho, para que fossem incorporados na produção de blocos não estruturais; além disso, a reciclagem de gesso chegou a mais de 2 mil toneladas em 2013.

A EVEN Construtora e Incorporadora S. A. possui um sistema para a reciclagem dos sacos de cimento, fazendo uma parceria com outras empresas e substituindo as caçambas por receptores de resíduos recicláveis, de forma que o cimento seja retirado dos sacos de modo mais eficiente, diminuindo a quantidade de resíduo de cimento que iria para os aterros sanitários.

O quadro 3 demonstra o GRI apresentado pela empresa, com a análise das informações efetivamente divulgadas e referenciadas pelos pesquisadores deste estudo, classificadas entre completa, parcial ou sem divulgação.

Quadro 3 - Categoria Ambiental da EVEN Construtora e Incorporadora S. A.

\begin{tabular}{|c|c|c|c|}
\hline Item & Assunto & Página & Status \\
\hline \multicolumn{4}{|c|}{ CATEGORIA AMBIENTAL } \\
\hline \multicolumn{4}{|c|}{ Aspecto: Materiais } \\
\hline DMA & Forma de gestão & 65 & Completo \\
\hline EN1 & Materiais usados por peso, valor ou volume & 65 & Completo \\
\hline EN2 & Percentual de materiais usados provenientes de reciclagem & 66 & Completo \\
\hline \multicolumn{4}{|c|}{ Aspecto: Energia } \\
\hline DMA & Forma de gestão & 67 & Completo \\
\hline EN3 & Consumo de energia dentro da organização & 67,69 & Completo \\
\hline EN4 & Consumo de energia fora da organização & 68,69 & Completo \\
\hline EN5 & Intensidade de energia & 69 & Completo \\
\hline EN6 & Redução no consumo de energia & 74 & Completo \\
\hline EN7 & Reduções nos requisitos de energia relacionados a produtos e serviços & 68,69 & Completo \\
\hline CRE1 & Energia na construção & 68 & Completo \\
\hline \multicolumn{4}{|c|}{ Aspecto: Água } \\
\hline DMA & Forma de gestão & 70 & Completo \\
\hline
\end{tabular}




\begin{tabular}{|c|c|c|c|}
\hline EN8 & Total de retirada de água por fonte & 70 & Completo \\
\hline EN9 & Fontes hídricas significativamente afetadas por retirada de água & 71 & Completo \\
\hline EN10 & Percentual e volume total de água reciclada e reutilizada & 71 & N.D. \\
\hline CRE2 & Água na construção & 70 & Completo \\
\hline \multicolumn{4}{|c|}{ Aspecto: Biodiversidade } \\
\hline DMA & Forma de gestão & 62 & Parcial \\
\hline EN11 & $\begin{array}{l}\text { Unidades operacionais próprias, arrendadas ou administradas dentro } \\
\text { ou nas adjacências de áreas protegidas e áreas de alto valor de } \\
\text { biodiversidade situadas fora de áreas protegidas }\end{array}$ & 64 & Completo \\
\hline EN12 & $\begin{array}{l}\text { Descrição de impactos significativos de atividades, produtos e } \\
\text { serviços sobre a biodiversidade em áreas protegidas e áreas de alto } \\
\text { valor de biodiversidade situadas fora de áreas protegidas }\end{array}$ & 64 & Completo \\
\hline EN13 & Habitats protegidos ou restaurados & 64 & Completo \\
\hline EN14 & $\begin{array}{l}\text { Número total de espécies na lista vermelha da IUCN (International } \\
\text { Union for Conservation of Nature) e em listas nacionais de conservação } \\
\text { com habitats situados em áreas afetadas por operaçães da } \\
\text { organização, discriminadas por nível de risco de extinção }\end{array}$ & 64 & Completo \\
\hline \multicolumn{4}{|c|}{ Aspecto: Emissões } \\
\hline DMA & Forma de gestão & 77 & Completo \\
\hline EN15 & Total de emissões diretas de gases causadores de efeito estufa (escopo 1) & 79 & Completo \\
\hline EN16 & $\begin{array}{l}\text { Total de emissões indiretas de gases causadores de efeito estufa } \\
\text { (escopo 2) }\end{array}$ & 79 & Completo \\
\hline EN17 & Outras emissões indiretas de gases causadores de efeito estufa (escopo 3) & 79 & Completo \\
\hline EN18 & Taxa de emissão de gases de efeito estufa & 80 & Completo \\
\hline EN19 & Redução de emissão de gases de efeito estufa & 80 & Completo \\
\hline EN20 & Emissões de substâncias que destroem a camada de ozônio (SDO) & 81 & Completo \\
\hline EN21 & $\begin{array}{c}\text { NOx (Óxido de nitrogênio), SOx (Compostos de enxofre) e outras } \\
\text { emissões atmosféricas significativas }\end{array}$ & 81 & Completo \\
\hline CRE3 & Emissão de gases de efeito estufa por construção & 81 & Completo \\
\hline CRE4 & Emissão de gases de efeito estufa de novas construções ou remodelação & 82 & Completo \\
\hline \multicolumn{4}{|c|}{ Aspecto: Efluentes e resíduos } \\
\hline DMA & Forma de gestão & 70 & Parcial \\
\hline EN22 & Descarte total de água, discriminado por qualidade e destinação & 70 & Parcial \\
\hline EN23 & Peso total de resíduos, por tipo médio de disposição & 84 & Completo \\
\hline EN24 & Número total e volume de vazamentos significativos & 86 & Completo \\
\hline EN25 & $\begin{array}{l}\text { Peso de resíduos transportados, importados, exportados ou tratados con- } \\
\text { siderados perigosos nos termos da Convenção da Basileia } 2^{1} \text { - Anexos I, II, } \\
\text { III e VIII, e percentual de resíduos transportados internacionalmente }\end{array}$ & 86 & Completo \\
\hline EN26 & $\begin{array}{l}\text { Identificação, tamanho, status de proteção e valor da biodiversidade de } \\
\text { corpos d'água e habitats relacionados significativamente afetados por } \\
\text { descartes de água e drenagem de água realizados pela organização }\end{array}$ & 71 & Completo \\
\hline \multicolumn{4}{|c|}{ Aspecto: Produtos e Serviços } \\
\hline DMA & Forma de gestão & 61,72 & Completo \\
\hline EN27 & $\begin{array}{c}\text { Iniciativas para mitigar os impactos ambientais de produtos e serviços } \\
\text { e a extensão da redução desses impactos }\end{array}$ & 61 & Completo \\
\hline EN28 & $\begin{array}{l}\text { Percentual de produtos e suas embalagens recuperados em relação ao } \\
\text { total de produtos vendidos, discriminado por categoria de produtos }\end{array}$ & 72 & Completo \\
\hline
\end{tabular}

1. Acordo que define e controla os movimentos transfronteiriços de resíduos perigosos e seu depósito. 


\begin{tabular}{|c|c|c|c|}
\hline DMA & Forma de gestão & 61 & Completo \\
\hline EN29 & $\begin{array}{c}\text { Valor monetário de multas significativas e número total de sanções } \\
\text { não monetárias aplicadas em decorrência da não conformidade com } \\
\text { leis e regulamentos ambientais }\end{array}$ & 64 & Completo \\
\hline \multicolumn{4}{|c|}{ Aspecto: Transporte } \\
\hline DMA & Forma de gestão & 77 & N.D. \\
\hline EN30 & $\begin{array}{l}\text { Impactos ambientais significativos do transporte de produtos e } \\
\text { outros bens e materiais utilizados nas operações da organização, bem } \\
\text { como do transporte dos trabalhadores }\end{array}$ & 81 & Completo \\
\hline \multicolumn{4}{|c|}{ Aspecto: Geral } \\
\hline DMA & Forma de gestão & 73 & Completo \\
\hline EN31 & Total de investimentos e gastos em proteção ambiental, por tipo & 72 & Completo \\
\hline CRE5 & $\begin{array}{l}\text { Terrenos e outros ativos remediados e na necessidade de remediação } \\
\text { para a terra existente ou pretendida }\end{array}$ & 71 & Completo \\
\hline CRE8 & $\begin{array}{c}\text { Tipo e número de certificação de sustentabilidade, classificação } \\
\text { e rotulagem de esquemas para construção nova, gerenciamento, } \\
\text { ocupação e reabilitação }\end{array}$ & 73 & Completo \\
\hline \multicolumn{4}{|c|}{ Aspecto: Avaliação ambiental de fornecedores } \\
\hline DMA & Forma de gestão & 53 & Completo \\
\hline EN32 & $\begin{array}{l}\text { Percentual de novos fornecedores selecionados com base em critérios } \\
\text { ambientais }\end{array}$ & 54 & Completo \\
\hline EN33 & $\begin{array}{l}\text { Impactos ambientais negativos significativos reais e potenciais na } \\
\text { cadeia de fornecedores e medidas tomadas a esse respeito }\end{array}$ & 54 & Completo \\
\hline \multicolumn{4}{|c|}{ Aspecto: Mecanismos de queixas e reclamações relativas a impactos ambientais } \\
\hline DMA & Forma de gestão & 64 & Completo \\
\hline EN34 & $\begin{array}{l}\text { Número de queixas e reclamações relacionadas a impactos ambientais } \\
\text { registradas, processadas e solucionadas por meio de mecanismo formal }\end{array}$ & 64 & Completo \\
\hline
\end{tabular}

Fonte: Dados da pesquisa (2015)

Segundo o GRI apresentado, a EVEN Construtora e Incorporadora S. A. divulgou 100\% dos itens constantes no GRI; no entanto, após a análise das informações que fazem parte do Relatório de Sustentabilidade da empresa, observou-se que alguns dos itens que apareciam como sendo divulgados, não foram identificados, como, por exemplo, o item EN10 - Percentual e volume total de água reciclada e reutilizada. No GRI, consta como divulgado na página 71 , porém, não há a divulgação do percentual e volume de água reciclada e reutilizada. Além disso, o item DMA do aspecto Transportes que, segundo o relatório, estaria disponível na página 77, não está completo, pois o relatório traz informações referentes a fornecedores, sem falar sobre a gestão de transportes.

Portanto, após a análise das informações efetivamente divulgadas, observou-se que foram expressos $96 \%$ dos itens propostos na categoria ambiental, e, desses itens divulgados, em apenas três deles foi identificada a divulgação de forma parcial.

Em relação ao aspecto de efluentes e resíduos, foi feita uma análise quanto ao comportamento dos dados relacionados a cada item dessa categoria e uma explanação relacionada à identificação de itens divulgados como parciais. 
Quadro 4 - Periodicidade de informação referente a cada item do aspecto efluentes e resíduos

\begin{tabular}{|c|c|c|c|c|}
\hline \multicolumn{2}{|r|}{ Aspecto: Efluentes e resíduos } & Página & Status & $\begin{array}{l}\text { Periodicidade de } \\
\text { informação }\end{array}$ \\
\hline DMA & Forma de gestão & 70 & Parcial & $\begin{array}{l}\text { Relativo ao ano } \\
\text { do relatório }\end{array}$ \\
\hline EN22 & $\begin{array}{l}\text { Descarte total de água, discriminado por } \\
\text { qualidade e destinação }\end{array}$ & 70 & Parcial & $\begin{array}{l}\text { Relativo ao ano } \\
\text { do relatório }\end{array}$ \\
\hline EN23 & $\begin{array}{l}\text { Peso total de resíduos, por tipo médio de } \\
\text { disposição }\end{array}$ & 84 & Completo & Informações trienal \\
\hline EN24 & $\begin{array}{l}\text { Número total e volume de vazamentos } \\
\text { significativos }\end{array}$ & 86 & Completo & $\begin{array}{l}\text { Não ocorreram } \\
\text { vazamentos }\end{array}$ \\
\hline EN25 & $\begin{array}{l}\text { Peso de resíduos transportados, importados, } \\
\text { exportados ou tratados considerados peri- } \\
\text { gosos nos termos da Convenção da Basileia } \\
2 \text { - Anexos I, II, III e VIII, e percentual de resíduos } \\
\text { transportados internacionalmente }\end{array}$ & 86 & Completo & $\begin{array}{l}\text { Não foram registrados } \\
\text { resíduos desse tipo }\end{array}$ \\
\hline EN26 & $\begin{array}{l}\text { Identificação, tamanho, status de proteção e } \\
\text { valor da biodiversidade de corpos d'água e ha- } \\
\text { bitats relacionados significativamente afetados } \\
\text { por descartes de água e drenagem de água } \\
\text { realizados pela organização }\end{array}$ & 71 & Completo & $\begin{array}{c}\text { Não houve corpos } \\
\text { d'água e habitats } \\
\text { significativamente } \\
\text { afetados }\end{array}$ \\
\hline
\end{tabular}

Fonte: Dados da pesquisa (2015)

Com base no Quadro 4, observa-se que os itens DMA - Efluentes e resíduos - e EN22 foram considerados como divulgação parcial. Quando analisado o relatório no que diz respeito à forma de gestão relacionada a efluentes e resíduos, percebe-se que a informação trazida trata tão somente da gestão relacionada aos efluentes, não demonstrando a forma de gestão dos resíduos; dessa forma, o item foi considerado como divulgação parcial. No item EN22, é solicitado que a empresa divulgue o descarte total de água, discriminando por qualidade e destinação, e, no relatório de sustentabilidade da empresa EVEN, foi divulgado que o total de água descartada é o mesmo de água consumida, ou seja, que toda a água consumida é descartada e que o descarte é feito na rede de tratamento oferecida pelas concessionárias locais. No entanto, a empresa não informa a separação relativamente à qualidade da água descartada; sendo assim, o item foi considerado como divulgação parcial.

No que se refere aos itens EN24, EN25 e EN26, a informação foi considerada completa, pois não houve ações que obrigassem a empresa a divulgar tais itens, como no item EN25, por exemplo, em que a empresa não divulgou número total e volume de vazamentos significativos pelo fato de não terem ocorrido vazamentos; por conseguinte, considera-se como informação completa.

No que diz respeito ao comportamento dos dados informados, foi analisado o item EN23, em que houve divulgação trienal da informação, referente aos anos de 2011, 2012 e 2013, como se pode ver na Tabela 1.

Tabela 1 - Quantidade de resíduos gerados

\begin{tabular}{cccc}
\hline Descrição & $\mathbf{2 0 1 1}$ & $\mathbf{2 0 1 2}$ & $\mathbf{2 0 1 3}$ \\
\hline Alvenaria e Concreto & $40.027,83$ & $43.283,35$ & $37.498,85$ \\
Recicláveis & $1.924,01$ & 881,17 & $1.867,58$ \\
Madeira & $5.168,14$ & $4.408,40$ & $6.874,87$ \\
Gesso & $4.102,66$ & $4.025,85$ & $3.527,95$ \\
Mix & $15.737,79$ & $12.777,49$ & $9.798,03$ \\
\hline Total & $\mathbf{6 6 . 9 6 0 , 4 3}$ & $\mathbf{6 5 . 3 7 6 , 2 6}$ & $\mathbf{5 9 . 5 6 7 , 2 8}$ \\
\hline
\end{tabular}

Fonte: Dados da pesquisa (2015) 
Com base nos dados informados, a empresa conseguiu uma redução na geração de resíduos sólidos, de 2,4\% de 2011 para 2012 e de 8,9\% de 2012 para 2013.

A evolução do comportamento dos resíduos sólidos pode ser vista no Gráfico 1.

Gráfico 1 - Geração de resíduos sólidos

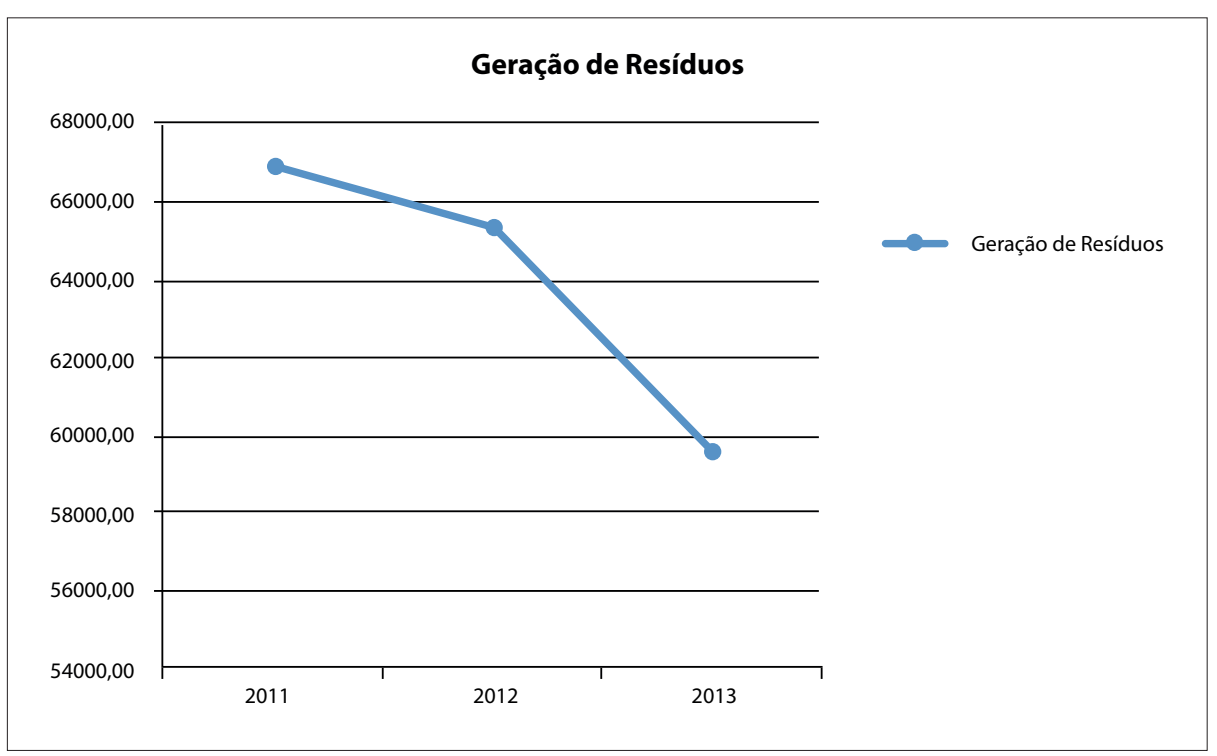

Fonte: Dados da pesquisa (2015)

No que concerne ao acumulado, a redução na geração de resíduos sólidos no período de 2011 a 2013 foi de 11\%.

\subsection{MRV Engenharia e Participações S. A.}

A empresa MRV Engenharia e Participações S. A. iniciou a divulgação do seu relatório de sustentabilidade em 2011, sendo o ano de 2014, utilizado para este trabalho, o terceiro em que foi divulgado o referido relatório.

Em 2011 ainda, a empresa iniciou uma ação de reaproveitamento de entulhos, com o intuito de reduzir o impacto dos resíduos gerados pelos seus empreendimentos, dando a correta destinação aos materiais não reutilizados, evitando que fossem levados aos aterros sanitários. Suas obras contam com baias de armazenamento para cada tipo de material (madeira, gesso, metal, sacaria, rejeito, entulho e recicláveis), com a finalidade de facilitar a correta destinação de cada tipo de material.

Em seu relatório de sustentabilidade, a empresa afirma ainda que parte dos materiais reutilizáveis é implantada nas próprias obras da MRV Engenharia e Participações S. A., visto que ela possui uma mini-indústria de reciclagem.

A empresa MRV Engenharia e Participações S. A. também utilizou o GRI para mostrar a evidenciação das informações no seu relatório de sustentabilidade. O Quadro 5 demonstra o GRI apresentado pela empresa, com a análise das informações efetivamente divulgada feita pelos autores, diferenciadas entre completa, parcial ou sem divulgação. 
Quadro 5 - Categoria Ambiental da MRV Engenharia e Participações S. A.

\begin{tabular}{|c|c|c|c|}
\hline Item & Assunto & Página & Situação \\
\hline \multicolumn{4}{|c|}{ CATEGORIA AMBIENTAL } \\
\hline \multicolumn{4}{|c|}{ Aspecto: Materiais } \\
\hline DMA & Forma de gestão & 66 & N.D. \\
\hline EN1 & Materiais usados por peso, valor ou volume & 66 & Completo \\
\hline EN2 & Percentual de materiais usados provenientes de reciclagem & N.D. & N.D. \\
\hline \multicolumn{4}{|c|}{ Aspecto: Energia } \\
\hline DMA & Forma de gestão & 64 & N.D. \\
\hline EN3 & Consumo de energia dentro da organização & 65 & Completo \\
\hline EN4 & Consumo de energia fora da organização & N.D. & N.D. \\
\hline EN5 & Intensidade de energia & N.D. & N.D. \\
\hline EN6 & Redução no consumo de energia & N.D. & N.D. \\
\hline EN7 & $\begin{array}{l}\text { Reduções nos requisitos de energia relacionados a produtos e } \\
\text { serviços }\end{array}$ & N.D. & N.D. \\
\hline CRE1 & Energia na construção & N.D. & N.D. \\
\hline \multicolumn{4}{|c|}{ Aspecto: Água } \\
\hline DMA & Forma de gestão & 64 & N.D. \\
\hline EN8 & Total de retirada de água por fonte & 65 & Parcial \\
\hline EN9 & Fontes hídricas significativamente afetadas por retirada de água & N.D. & N.D. \\
\hline EN10 & Percentual e volume total de água reciclada e reutilizada & 65 & Completo \\
\hline CRE2 & Água na construção & N.D. & N.D. \\
\hline \multicolumn{4}{|c|}{ Aspecto: Biodiversidade } \\
\hline DMA & Forma de gestão & N.D. & N.D. \\
\hline EN11 & $\begin{array}{l}\text { Unidades operacionais próprias, arrendadas ou administradas } \\
\text { dentro ou nas adjacências de áreas protegidas e áreas de alto } \\
\text { valor de biodiversidade situadas fora de áreas protegidas }\end{array}$ & N.D. & N.D. \\
\hline EN12 & $\begin{array}{l}\text { Descrição de impactos significativos de atividades, produtos e } \\
\text { serviços sobre a biodiversidade em áreas protegidas e áreas de } \\
\text { alto valor de biodiversidade situadas fora de áreas protegidas }\end{array}$ & N.D. & N.D. \\
\hline EN13 & Habitats protegidos ou restaurados & N.D. & N.D. \\
\hline EN14 & $\begin{array}{c}\text { Número total de espécies na lista vermelha da IUCN e em listas } \\
\text { nacionais de conservação com habitats situados em áreas } \\
\text { afetadas por operações da organização, discriminadas por } \\
\text { nível de risco de extinção }\end{array}$ & N.D. & N.D. \\
\hline \multicolumn{4}{|c|}{ Aspecto: Emissões } \\
\hline DMA & Forma de gestão & N.D. & Completo \\
\hline EN15 & $\begin{array}{l}\text { Total de emissões diretas de gases causadores de efeito estufa } \\
\text { (escopo 1) }\end{array}$ & N.D. & Completo \\
\hline EN16 & $\begin{array}{l}\text { Total de emissões indiretas de gases causadores de efeito estufa } \\
\text { (escopo 2) }\end{array}$ & N.D. & Completo \\
\hline EN17 & $\begin{array}{l}\text { Outras emissões indiretas de gases causadores de efeito estufa } \\
\text { (escopo 3) }\end{array}$ & N.D. & Completo \\
\hline EN18 & Taxa de emissão de gases de efeito estufa & N.D. & N.D. \\
\hline EN19 & Redução de emissão de gases de efeito estufa & N.D. & N.D. \\
\hline EN20 & $\begin{array}{l}\text { Emissões de substâncias que destroem a camada de ozônio } \\
\text { (SDO) }\end{array}$ & N.D. & N.D. \\
\hline EN21 & NOx, SOx e outras emissões atmosféricas significativas & N.D. & N.D. \\
\hline CRE3 & Emissão de gases de efeito estufa por construção & N.D. & N.D. \\
\hline
\end{tabular}




\begin{tabular}{|c|c|c|c|}
\hline CRE4 & $\begin{array}{l}\text { Emissão de gases de efeito estufa de novas construções } \\
\text { ou remodelação }\end{array}$ & N.D. & N.D. \\
\hline \multicolumn{4}{|c|}{ Aspecto: Efluentes e resíduos } \\
\hline DMA & Forma de gestão & 68 & Parcial \\
\hline EN22 & Descarte total de água, discriminado por qualidade e destinação & N.D. & N.D. \\
\hline EN23 & Peso total de resíduos, por tipo médio de disposição & N.D. & N.D. \\
\hline EN24 & Número total e volume de vazamentos significativos & $\begin{array}{c}\text { Não houve } \\
\text { derramamentos }\end{array}$ & Completo \\
\hline EN25 & $\begin{array}{l}\text { Peso de resíduos transportados, importados, exportados ou trata- } \\
\text { dos considerados perigosos nos termos da Convenção da Basileia } \\
2 \text { - Anexos I, II, III e VIII, e percentual de resíduos transportados } \\
\text { internacionalmente }\end{array}$ & N.D. & N.D. \\
\hline EN26 & $\begin{array}{l}\text { Identificação, tamanho, status de proteção e valor da } \\
\text { biodiversidade de corpos d'água e habitats relacionados } \\
\text { significativamente afetados por descartes de água e } \\
\text { drenagem de água realizados pela organização }\end{array}$ & N.D. & N.D. \\
\hline \multicolumn{4}{|c|}{ Aspecto: Produtos e Serviços } \\
\hline DMA & Forma de gestão & N.D. & N.D. \\
\hline EN27 & $\begin{array}{c}\text { Iniciativas para mitigar os impactos ambientais de produtos e } \\
\text { serviços e a extensão da redução desses impactos }\end{array}$ & N.D. & N.D. \\
\hline EN28 & $\begin{array}{c}\text { Percentual de produtos e suas embalagens recuperados } \\
\text { em relação ao total de produtos vendidos, discriminado por } \\
\text { categoria de produtos }\end{array}$ & N.D. & N.D. \\
\hline \multicolumn{4}{|c|}{ Aspecto: Conformidade } \\
\hline DMA & Forma de gestão & N.D. & N.D. \\
\hline EN29 & $\begin{array}{l}\text { Valor monetário de multas significativas e número total de } \\
\text { sanções não monetárias aplicadas em decorrência da não } \\
\text { conformidade com leis e regulamentos ambientais }\end{array}$ & N. D. & N.D. \\
\hline \multicolumn{4}{|c|}{ Aspecto: Transporte } \\
\hline DMA & Forma de gestão & N.D. & N.D. \\
\hline EN30 & $\begin{array}{l}\text { Impactos ambientais significativos do transporte de produtos e } \\
\text { outros bens e materiais utilizados nas operações da organização, } \\
\text { bem como do transporte dos trabalhadores }\end{array}$ & N.D. & N.D. \\
\hline \multicolumn{4}{|c|}{ Aspecto: Geral } \\
\hline DMA & Forma de gestão & N.D. & N.D. \\
\hline EN31 & Total de investimentos e gastos em proteção ambiental, por tipo & N.D. & N.D. \\
\hline CRE5 & $\begin{array}{l}\text { Terrenos e outros ativos remediados e na necessidade de } \\
\text { remediação para a terra existente ou pretendida }\end{array}$ & N.D. & N.D. \\
\hline CRE8 & $\begin{array}{c}\text { Tipo e número de certificação de sustentabilidade, classificação } \\
\text { e rotulagem de esquemas para construção nova, gerenciamento, } \\
\text { ocupação e reabilitação }\end{array}$ & N.D. & N.D. \\
\hline \multicolumn{4}{|c|}{ Aspecto: Avaliação ambiental de fornecedores } \\
\hline DMA & \begin{tabular}{|l|} 
Forma de gestão \\
\end{tabular} & N.D. & N.D. \\
\hline EN32 & $\begin{array}{l}\text { Percentual de novos fornecedores selecionados com base em } \\
\text { critérios ambientais }\end{array}$ & N. D. & N. D. \\
\hline EN33 & $\begin{array}{l}\text { Impactos ambientais negativos significativos reais e potenciais na } \\
\text { cadeia de fornecedores e medidas tomadas a esse respeito }\end{array}$ & N.D. & N.D. \\
\hline \multicolumn{4}{|c|}{ Aspecto: Mecanismos de queixas e reclamações relativas a impactos ambientais } \\
\hline DMA & Forma de gestão & N.D. & N.D. \\
\hline EN34 & $\begin{array}{c}\text { Número de queixas e reclamações relacionadas a impactos am- } \\
\text { bientais registradas, processadas e solucionadas por meio } \\
\text { de mecanismo formal }\end{array}$ & N.D. & N.D. \\
\hline
\end{tabular}

Fonte: Dados da pesquisa (2015) 
No GRI apresentado pela empresa MRV Engenharia e Participações S. A., dos 52 itens apresentados no modelo GRI na Categoria Ambiental, a empresa informou que havia divulgado nove itens (considerando o item EN24 como divulgação), ou seja, apenas 17,3\%. No entanto, após a análise das informações constantes no Relatório de Sustentabilidade da empresa, notou-se que alguns itens que estavam como se houvessem sido divulgados, na verdade, não estavam disponíveis no relatório, como, por exemplo, o item DMA Materiais, que, segundo o GRI, constava na página 66 a forma de gestão relacionada ao aspecto de materiais. Contudo, ao verificar a informação, observou-se que constava apenas a especificação dos materiais e não a forma de gestão. Além disso, constatou-se que alguns itens que estavam como se não houvessem sido divulgados, na verdade, estavam divulgados no relatório. Esse caso ocorreu no aspecto efluentes, em que os itens DMA - Efluentes, EN15, EN16 e EN17 constavam como não divulgados no GRI apresentado pela empresa, mas a informação estava disponível. Assim sendo, foi considerado como divulgação completa.

Após a análise das informações efetivamente divulgadas, observou-se que $19 \%$ dos itens referentes à categoria ambiental foram divulgados, e desses, em dois itens foi identificada a divulgação parcial.

Na empresa EVEN, pouco se divulgou em relação ao aspecto de efluentes e resíduos, portanto, não houve dados para serem avaliados. No que tange a esse aspecto, na referida empresa, observou-se que o item DMA - Efluentes e resíduos foi considerado como publicação parcial, dado que, além de não ter sido encontrada informação referente à gestão de efluentes, a página indicada no GRI da empresa como constando as informações está equivocada, visto que a informação referente à forma de gestão de resíduos foi encontrada na página anterior à informada, 67. Consequentemente, pelo fato de não aparecerem informações referentes à gestão de resíduos, o item foi considerado como divulgação parcial.

\section{CONCLUSÃO}

Com base na pesquisa feita nos relatórios de sustentabilidade das duas empresas do setor listadas na BM\&FBOVESPA, que possuem relatório de sustentabilidade, observou-se que ambas não só tratam da gestão de resíduos sólidos em seus relatórios de sustentabilidade, como das práticas adotadas para a correta destinação e reutilização ou reciclagem dos resíduos. No entanto, constatou-se que uma empresa já vem elaborando e divulgando seu relatório há mais anos, desde 2008, enquanto a outra elabora e publica seu relatório de sustentabilidade somente desde 2011.

Observou-se ainda que a empresa EVEN Construtora e Incorporadora S. A. divulgou um número maior de informações sobre a gestão dos seus resíduos sólidos, inclusive a quantidade de resíduos gerada em um determinado período. Além disso, ela possui um sistema para reciclagem dos sacos de cimento, o que reduziu os restos de cimento nos aterros sanitários. Em contrapartida, a empresa MRV Engenharia possui um sistema de reutilização de resíduos que são reciclados dentro de suas próprias instalações, pela implantação de uma mini-indústria de reciclagem.

No que se refere à Categoria Ambiental, a empresa EVEN Construtora e Incorporadora S. A. evidenciou $100 \%$ dos itens do seu GRI, enquanto a empresa MRV Engenharia e Participações demonstrou apenas 17,3\%. Após a busca das informações efetivamente disponibilizadas no relatório de sustentabilidade das empresas, observou-se que foram evidenciadas um número menor de informações, por parte da empresa EVEN Construtora e Incorporadora S. A. De $96 \%$ de itens divulgados reduz-se para $90,4 \%$ se considerar apenas itens completos para fins de evidenciação.

Em contrapartida, a empresa MRV Engenharia e Participações apresentou um aumento da sua evidenciação após a análise das informações constantes no relatório de sustentabilidade. No seu GRI, a empresa afirmava evidenciar $17,3 \%$ dos itens e, depois da análise, esse percentual passou para $19 \%$, o que mostra que mesmo a construção civil sendo uma área em expansão e grande geradora de resíduos, as empresas ainda não evidenciam as informações quanto aos impactos ambientais inerentes ao empreendimento.

O estudo apresenta que a MRV e a EVEN evidenciaram um número pequeno de itens entre as categorias estabelecidas no GRI, destacando-se apenas uma que expôs os indicadores da Categoria Ambiental de 
forma representativa. Além disso, verificou-se que, na análise das informações efetivamente divulgadas, as duas empresas sustentam certas informações que, na verdade, não constavam no relatório.

Por fim, o estudo apresentou contribuições teóricas ao fornecer observações importantes sobre o tema, demonstrando a dificuldade das empresas quanto à disponibilização de informações referente ao relatório de sustentabilidade. Outra contribuição do estudo identifica pouca governança corporativa entre a população, uma vez que no segmento da construção civil, duas empresas da amostra elaboram e divulgam seus relatórios de sustentabilidade. No que se refere àquelas que divulgam, há uma lacuna quanto aos indicadores ambientais, já que alguns itens não são informados ou informados parcialmente.

\title{
CONSTRUCTION WASTE MANAGEMENT : AN ANALYSIS OF THE GRI REPORT OF COMPANIES LISTED ON THE BM\&FBOVESPA STOCK EXCHANGE
}

\begin{abstract}
A growing industry in Brazil is construction; however, it causes significant impact to the environment, part of which is a high level of physical waste. In light of these circumstances, the objective of the present work is the identification and analysis of the waste management-related content disclosed in the sustainability reports of the construction companies listed on the BM\&FBOVESPA Stock Exchange. To reach this objective, the sustainability reports of construction companies listed on the BM\&FBOVESPA Stock Exchange were examined. The results showed that a small part of the listed companies disclose the sustainability report and that of the two companies identified, after analyzing the information effectively disclosed, one presented data relating to approximately $96 \%$ of the GRI Environmental Category items and the other showed only about 19\% of the items. Besides, in both companies items were identified whose disclosure was made partially or was not even made. The study shows that, although the construction industry is expanding and producing physical waste, very few companies in the area disclose a socio-environmental report.
\end{abstract}

Keywords: Physical waste. Construction. Environmental sustainability.

\section{REFERÊNCIAS}

AZEVEDO, Gardênia Oliveira David de; KIPERSTOK, Asher; MORAES, Luiz Roberto Santos. Resíduos da construção civil em Salvador: os caminhos para uma gestão sustentável. [2006]. Disponível em: <http://www.scielo.br/scielo. php?script=sci_arttext\&pid=S1413-41522006000100009\&lng=pt\&nrm=isso >. Acesso em: 10 maio 2014.

BAPTISTA, Joel Vieira Junior; ROMANEL, Celso. Sustentabilidade na indústria da construção: uma logística para reciclagem dos resíduos de pequenas obras. [2013]. Disponível em: $<$ http://www.scielo.br/scielo. php?pid=S2175-33692013000200004\&script=sci_arttext $>$. Acesso em: 30 jul. 2014.

BEUREN, Ilse Maria; DOMENICO, Daniela Di; CORDEIRO, Adilson. Análise de indicadores do Environmental Management Accounting evidenciados no Global Reporting Initiative. [2013]. Disponível em: <http:// www.spell.org.br/documentos/ver/31294/analise-de-indicadores-do-environmental-managementaccounting-evidenciados-no-global-reporting-initiative>. Acesso em: 04 ago. 2014.

BRASIL. Lei 9.985 de 18 de julho de 2000. Institui o Sistema Nacional de Unidades de Conservação da Natureza - SNUC. [2000]. Disponível em: <http://www.mma.gov.br/port/conama/legiabre.cfm?codlegi=322>. Acesso em: 25 mar. 2015.

BRASIL. Resolução no. 307/2002. [2002]. Disponível em: <http://www.mma.gov.br/port/conama/legiabre. cfm?codlegi=307>. Acesso em: 04 maio 2014. 
BRASIL. Lei 11.445 de 05 de janeiro de 2007. Estabelece diretrizes nacionais para o saneamento básico e para a política federal de saneamento básico. [2007]. Disponível em: <http://www.planalto.gov.br/ccivil_03/_ ato2007-2010/2007/lei/l11445.htm>. Acesso em: 04 maio 2014.

BRASIL. Lei 12.305 de 2 de agosto de 2010. Institui a Política Nacional de Resíduos Sólidos. [2010]. Disponível em: <http://www.mma.gov.br/port/conama/legiabre.cfm?codlegi=636>. Acesso em: 04 maio 2014.

CENTRO DE GESTÃO E ESTUDOS ESTRATÉGICOS (CGEE). Relatório Prospectivo Setorial 2009. Brasília: CGEE, 2009.

CERVO, Amado Luiz; BERVIAN, Pedro Alcino. Metodologia científica. 5. ed. São Paulo: Person Prentice Hall, 2002.

CRESWELL, John W. Projeto de pesquisa: métodos qualitativo, quantitativo e misto. 2. ed. Porto Alegre: Artmed, 2007.

FERREIRA, Denize Demarche Minatti; NOSCHANG, Cleuza Regina Tomaz; FERREIRA, Luiz Felipe. Gestão de resíduos da construção civil e de demolição: contribuições para a sustentabilidade ambiental. In: Congresso Nacional de Excelência em Gestão, 5., 2009. Anais... Niterói, RJ: UFF, 2009. p. 1-23.

FERREIRA, Luiz Felipe et al. Indicadores de Sustentabilidade Empresarial: uma comparação entre os indicadores do balanço social IBASE e relatório de sustentabilidade segundo as diretrizes da Global Reporting Initiative (GRI). In: Congresso Nacional de Excelência em Gestão, 5., 2009. Anais... Niterói, RJ: UFF, 2009. p. 1-15.

GIL, A. C. Como Elaborar Projetos de Pesquisa. 4. ed. São Paulo: Atlas, 2002.

GLOBAL REPORTING INITIATIVE (GRI). Diretrizes para relatório de sustentabilidade. [2006]. Disponível em: $<$ www.globalreporting.org>. Acesso em: 04 ago. 2014.

IPEA - INSTITUTO DE PESQUISA ECONÔMICA APLICADA. Diagnóstico dos Resíduos Sólidos da Construção Civil. [2012]. Disponível em: <http://www.ipea.gov.br/agencia/images/stories/PDFs/ relatoriopesquisa/120911_relatorio_construcao_civil.pdf>. Acesso em: 19 mar. 2015.

NOSSA, Valcemiro. Disclosure ambiental: uma análise do conteúdo dos relatórios ambientais de empresas do setor de Papel e Celulose em nível internacional. 2002. Tese (Doutorado) - Universidade de São Paulo, São Paulo.

ROSA, Fabricia Silva da et al. Estudo sobre o Global Report Initiative de empresas de energia elétrica dos Estados Unidos, do Brasil e da Espanha no período de 1999 a 2010. [2013]. Disponível em: <http:// www.spell.org.br/documentos/ver/10431/estudo-sobre-o-global-report-initiative-de- empresas-de-energiaeletrica-dos-estados-unidos--do-brasil-e-da-espanha-no-periodo-de-1999-a-2010>. Acesso em: 04 ago. 2014.

SABADO, J. O. S.; FARIAS FILHO, M. C. Ações de sustentabilidade influenciando o isomorfismo no campo das organizações da indústria de construção civil. Reuna, Belo Horizonte, v. 16, n. 4, p. 27-42, 2011.

SILVA, Paulo José et al. Políticas e práticas de gestão ambiental: uma análise da gestão dos resíduos da construção civil na cidade de Belo Horizonte (MG). [2006]. Disponível em: < http://www.spell.org.br/ documentos/ver/20675/politicas-e- praticas-de-gestao-ambiental--uma-analise-da-gestao-dos-residuos-daconstrucao-civil-na- cidade-de-belo-horizonte--mg->. Acesso em: 30 jul. 2014. 
SILVA, Vinicius Arcanjo da; FERNANDES, André Luís Teixeira. Cenário do gerenciamento dos Resíduos da Construção e Demolição (RCD) em Uberaba-MG. Soc. \& Nat., Uberlândia, Uberlândia, ano 24, n. 2, p. 333344, maio/ago. 2012.

SPADOTTO, Aryane et al. Impactos ambientais causados pela construção civil. Unoesc \& Ciência, Joaçaba, v. 2, n. 2, p. 173-180, jul./dez. 2011.

TOLEDO, Raquel; ABREU, Aline França de; JUNGLES, Antonio Edesio. A Difusão de Inovações Tecnológicas na Indústria da Construção Civil. In: Encontro Nacional de Tecnologia do Ambiente Construído (ENTAC), 8., 2000, Salvador. Anais... Salvador: ANTAC, 2000. p. 1-10. 